\title{
EFFECTS OF CARBON FIBRE \\ ON PERFORMANCE PROPERTIES \\ OF ASPHALT MIXTURES
}

\author{
TACETTIN GECKIL ${ }^{1 *}$, PERVIZ AHMEDZADE ${ }^{2}$ \\ ${ }^{1}$ Dept of Civil Engineering, Faculty of Engineering, Inonu University, \\ Malatya, Turkey \\ ${ }^{2}$ Dept of Civil Engineering, Faculty of Engineering, Ege University, Izmir, Turkey
}

Received 06 November 2018; accepted 8 October 2019

\begin{abstract}
In this study, the effects of carbon fibre on improving the performance characteristics of asphalt mixtures were investigated. To this end, four percentages of carbon fibre $(0 \%, 0.3 \%, 0.5 \%$, and $0.7 \%$ by weight of bitumen) were used as an additive in asphalt mixtures. The mechanical properties of prepared mixture specimens were investigated using tests such as Marshall Stability and flow, Indirect Tensile Stiffness Modulus, Creep Stiffness, Indirect Tensile Strength, and moisture resistance. The results of tests applied to asphalt mixtures showed that the carbon fibre additive increased the resistance to shear stress by $25 \%$, the fatigue life by $51 \%$ at $40{ }^{\circ} \mathrm{C}$ and the permanent deformation resistance by 2.25 times at $60^{\circ} \mathrm{C}$. It also improved the resistance of mixtures to moisture damage by increasing the durability and cohesion of asphalt mixtures. Experimental results indicated that the carbon fibre provided a positive contribution to the performance properties of asphalt pavements.
\end{abstract}

Keywords: asphalt, carbon fibre, Marshall stability, moisture resistance, rutting resistance, stiffness modulus.

\footnotetext{
* Corresponding author. E-mail: tacettin.geckil@inonu.edu.tr

Tacettin GECKIL (ORCID ID 0000-0001-8070-6836)

Perviz AHMEDZADE (ORCID ID 0000-0001-8348-5901)

Copyright (C) 2020 The Author(s). Published by RTU Press

This is an Open Access article distributed under the terms of the Creative Commons Attribution License (http://creativecommons.org/licenses/by/4.0/), which permits unrestricted use, 


\section{Introduction}

It is generally known that external factors such as traffic volume and environment affect the performance of asphalt pavements. Mainly, these stresses occur in the pavement layer because of high traffic decreasing the service life of the pavement and as a result, increasing the maintenance cost. The problems need to be eliminated by adopting advanced design methods or by using asphalt modifiers to improve the mechanical properties of pavements. Asphalt modification offers a solution to improve bitumen-based pavement deficiencies and thereby results in better asphalt pavement performance (Abtahi, Sheikhzadeh, \& Hejazi, 2010; Liu, Wu, Li, \& Gao, 2008; Xiong, Fang, Xu, Guan, \& Liu, 2015).

Various modifiers such as fly ash, sulfur, carbon black, bottom ash, red mud, asphalt rubber and polymers have been used to improve the performance properties of bitumens (Cong, Xu, \& Chen, 2014; Lima, Thives, Haritonovs, \& Bajars, 2017; Vaitkus, Gražulytė, Vorobjovas, Šernas, \& Kleızıenė, 2018; Xiong, Fang, Xu, Guan, \& Liu, 2015). Although polymers have generally been selected as an additive to improve performance properties of bitumens, a variety of fibre types have been used (Cleven, 2000). A multitude of fibre materials such as polypropylene fibre, glass fibre, polyester fibre, cellulose fibre, carbon fibre, asbestos fibre are introduced in the market (Abtahi, Sheikhzadeh, \& Hejazi, 2010; Krayushkina, Prentkovskis, Bieliatynskyi, Gigineishvili, Skrypchenko, Laurinavičius, Gopalakrishnan, \& Tretjakovas, 2016; Lee, Rust, Hamouda, Kim, \& Borden, 2005; Serfass \& Samanos,1996; Wu, Ye, $\mathrm{Li}, \&$ Yue, 2007). The use of carbon fibre in asphalt mixtures has been investigated by many researchers (Jahromi \& Khodaii, 2008; Liu \& Wu, 2011).

The carbon fibre (CF) is a fibrous material having a micro graphite crystal structure made by fibrillation of acrylic resin from oil/coal pitch and then by being given heat treatment. The carbon fibres have low specific gravity, superior mechanical properties (high tensile modulus, high tensile strength) and impressive performances (high heat conductivity, chemical stability, low thermal expansion coefficient, electric conductivity, heat resistance). These properties of CFs make them very popular in civil engineering (reinforcing and repairing material for building), military, chemical, and automotive industry. Other application areas using CF have been the road pavements (Chung, D. D., \& Chung, D. 2012; Morgan, 2005; Okuda, 1990). Because of their genetic compatibility with asphalt and their superior mechanical properties, CFs offer excellent potential for asphalt or mixture modification. However, the effect of $\mathrm{CF}$ on the performance of mixtures has been partially understood due to the lack of understanding about optimising the fibre 
properties (surface texture, length, diameter). Notably, it is thought that the length of fibre is a critical factor that affects the performance of CF-modified mixtures. If the fibres are too long, some of them will lump together, and the fibres do not blend well with the asphalt-aggregate mixture.

Similarly, if very short fibres are used in the mixtures, it will not provide a strengthening effect (Cleven, 2000). Two different methods known as wet and dry processes are used to place the fibres into the asphalt mixture. In the wet process, the fibres are blended with the bitumen before being added into the mixture. In the dry process, generally preferred for various reasons, the fibres are blended with the aggregate before the binder is added. Experimentally, the dry process is the easiest to apply and allows for the best fibre distribution in the blend. In the meantime, as the fibres will not melt in the asphalt, there are no other specific benefits for the wet process. In addition, field studies on fibre-reinforced asphalt mixtures have ensured the acceptance of dry processing, possibly due to the production problems associated with direct fibres entry into the asphalt (Echols, 1989; Munn, 1989). Another reason for using the dry process is that it minimises the significant problems associated with the gathering or agglomeration of the fibres in the mixture (Labib \& Maher, 1999). The effects of carbon fibres on the performance properties of mixtures have been investigated in many previous studies. In these studies, were investigated the properties of the CF-modified mixtures through tests such as Marshall Stability, indirect tension, creep, and repeated load Indirect Tensile Stiffness test to determine the fatigue resistance. The results showed that the addition of CF resulted in increased stability of the mixture, decreased flow and air voids. The results also indicated that the fatigue life and the permanent deformation resistance of the mixtures improved (Jahromi \& Khodaii, 2008; Serfass \& Samanos, 1996; Wang, Gao, Ai, \& Zhao, 2014; Zhao, 2012). The results of a research conducted by Fitzgerald (2000) showed that the mechanical and electrical conductivity properties of CF-modified asphalt mixtures improved. Cleven (2000) subjected CF-reinforced asphalt mixtures to mechanical tests such as Indirect Tensile Strength (ITS), flexural beam fatigue, repeated load permanent deformation and diametral resilient modulus test. The results showed that the CF-additive mixtures were harder, resistant to permanent deformation, and had a high tensile strength at low temperatures. Besides, many researchers have used a variety of modifiers such as carbon black, graphite, and CF to improve both the mechanical and electrical conductivity properties of asphalt mixtures. However, it has been determined that the use of $\mathrm{CF}$ in asphalt mixtures further improves the electrical conductivity of the pavement and its performance in the
Fibre on Performance Properties of Asphalt Mixtures 
pavement is better than graphite and carbon black (Cong, Xu, \& Chen, 2014; García, Schlangen, van de Ven, \& Liu, 2009; Liu, X., Liu, W., Wu, \& Wang, 2014; Liu \& Wu, 2011; Liu, Wu, Li, \& Gao, 2008).

The purpose of this study is to investigate the effects of carbon fibre (CF) that is used as an additive in mixture modification, on the performance properties of asphalt mixtures to build pavements with high stability, permanent deformation, and moisture resistance.

\section{Experimental}

\subsection{Materials}

In this research, three materials were used: asphalt binder, crushed limestone aggregate and carbon fibre (CF). The bitumen with $70 / 100$ penetration grade used in the study has been obtained from the Turkish Petroleum Refineries Corporation (TUPRAS). The physical properties of base bitumen were determined by conventional tests such as penetration, softening point, ductility. The test results are given in Table 1. The gradation of combined limestone aggregate used in the study is given in Table 2, and its physical properties are given in Table 3.

Table 1. Physical properties of the base bitumen

\begin{tabular}{|c|c|c|}
\hline Properties & Standard & Results \\
\hline $\begin{array}{l}\text { Penetration, } \\
0.1 \mathrm{~mm}, 100 \mathrm{~g}, 5 \mathrm{~s}\end{array}$ & $\begin{array}{l}\text { ASTM D5 Standard Test Method for } P \text { enetration } \\
\text { of Bituminous Materials }\end{array}$ & 90 \\
\hline Softening point, ${ }^{\circ} \mathrm{C}$ & $\begin{array}{l}\text { ASTM D36/D36M Standard Test Method for Softening Point } \\
\text { of Bitumen (Ring-and-Ball Apparatus) }\end{array}$ & 48.2 \\
\hline $\begin{array}{l}\text { Ductility, } \\
\mathrm{cm} \text { at } 25^{\circ} \mathrm{C}, \min \end{array}$ & $\begin{array}{l}\text { ASTM D113 Standard Test Method for Ductility of Asphalt } \\
\text { Materials }\end{array}$ & 100 \\
\hline Fraass breaking point, ${ }^{\circ} \mathrm{C}$ & $\begin{array}{l}\text { EN 12593:2015 Bitumen and Bituminous Binders - } \\
\text { Determination of the Fraass Breaking Point }\end{array}$ & -27.2 \\
\hline $\begin{array}{l}\text { Kinematic viscosity, } \\
135^{\circ} \mathrm{C}, \mathrm{um}^{2} / \mathrm{s}\end{array}$ & $\begin{array}{l}\text { ASTM D2170/D2170M Standard Test Method for Kinematic } \\
\text { Viscosity of Asphalts }\end{array}$ & 354 \\
\hline $\begin{array}{l}\text { Specific gravity, } \\
\mathrm{g} / \mathrm{cm}^{3} \text { at } 25^{\circ} \mathrm{C}\end{array}$ & $\begin{array}{l}\text { ASTM D70 Standard Test Method for Density of Semi-Solid } \\
\text { Asphalt Binder (Pycnometer Method) }\end{array}$ & 1.036 \\
\hline Penetration Index, PI & - & -0.15 \\
\hline $\begin{array}{l}\text { Penetration viscosity } \\
\text { number, PVN }\end{array}$ & - & -0.53 \\
\hline
\end{tabular}


Table 2. Combined aggregate gradation

\begin{tabular}{ccc}
\hline \multicolumn{1}{c}{ Sieve size } & Total cumulative passing, \% \\
\hline $19.000 \mathrm{~mm} \quad\left(3 / 4^{\prime \prime}\right)$ & 100 \\
$12.500 \mathrm{~mm} \quad\left(1 / 2^{\prime \prime}\right)$ & 95 \\
$9.500 \mathrm{~mm} \quad\left(3 / 8^{\prime \prime}\right)$ & 88 \\
$4.750 \mathrm{~mm} \quad(\# 4)$ & 65 \\
$2.000 \mathrm{~mm} \quad(\# 8)$ & 39 \\
$1.180 \mathrm{~mm} \quad(\# 16)$ & 24 \\
$0.600 \mathrm{~mm} \quad(\# 30)$ & 18 \\
$0.300 \mathrm{~mm} \quad(\# 50)$ & 14 \\
$0.150 \mathrm{~mm} \quad(\# 100)$ & 10 \\
$0.075 \mathrm{~mm} \quad(\# 200)$ & 6 \\
\hline
\end{tabular}

A commercial CF yarn (Tairyfil TC-35/12K) was used as an additive in the study. Physical properties of CF that have scarcely been used in any study before are given in Table 4 .

The morphologies of the carbon fibre and the asphalt mixture containing carbon fibre were investigated using Scanning Electron Microscope (SEM) with Leo Evo 40VP that is operated at $20 \mathrm{kV}$ voltage, and the working distance was chosen as $13-33 \mathrm{~mm}$. Figure 1 shows the SEM images of carbon fibre and asphalt mixture containing carbon fibre.

Table 3. Properties of limestone mineral aggregate

\begin{tabular}{|c|c|c|c|c|}
\hline \multirow{2}{*}{ Properties } & \multirow{2}{*}{ Standard } & \multicolumn{3}{|c|}{ Aggregate } \\
\hline & & Coarse & Fine & Filler \\
\hline $\begin{array}{l}\text { Abrasion loss, \% } \\
\text { (Los Angeles) }\end{array}$ & $\begin{array}{l}\text { ASTM C131 Standard Test Method for Resistance } \\
\text { to Degradation of Small-Size Coarse Aggregate } \\
\text { by Abrasion and Impact in the Los Angeles Machine }\end{array}$ & 29.000 & - & - \\
\hline $\begin{array}{l}\text { Frost action, \% } \\
\text { (with } \mathrm{Na}_{2} \mathrm{SO}_{4} \text { ) }\end{array}$ & $\begin{array}{l}\text { ASTM C-88 Standard Test Method for Soundness } \\
\text { of Aggregates by Use of Sodium Sulfate or Magnesium } \\
\text { Sulfate }\end{array}$ & 3.740 & - & - \\
\hline \multirow{3}{*}{$\begin{array}{l}\text { Specific gravity, } \\
\mathrm{g} / \mathrm{cm}^{3}\end{array}$} & $\begin{array}{l}\text { ASTM C-127 Standard Test Method for Relative Density } \\
\text { (Specific Gravity) and Absorption of Coarse Aggregate }\end{array}$ & 2.627 & - & - \\
\hline & $\begin{array}{l}\text { ASTM C-128 Standard Test Method for Relative } \\
\text { Density (Specific Gravity) and Absorption of Fine } \\
\text { Aggregate }\end{array}$ & - & 2.639 & - \\
\hline & $\begin{array}{l}\text { ASTM D- } 854 \text { Standard Test Methods for Specific } \\
\text { Gravity of Soil Solids by Water Pycnometer }\end{array}$ & - & - & 2.632 \\
\hline
\end{tabular}


Table 4. Physical properties of carbon fibre

\begin{tabular}{lc}
\hline \multicolumn{1}{c}{ Properties } & Carbon fibre (TC-35/12K) \\
\hline Number of filaments & 12000 \\
Yield texture, g/1000m & 720 \\
Tensile strength, ksi & 580 \\
Tensile modulus, msi & 35 \\
Elongation, \% & 1.6 \\
Density, g/cm ${ }^{2}$ & 1.8 \\
Filament diameter, $\mu$ & 6.5 \\
\hline
\end{tabular}

As observed in Figure 1a, carbon fibre has a tube shape with a uniform distribution. On the other hand, SEM images of the asphalt mixture containing carbon fibre reflect the intricate structure (Figure $1 \mathrm{~b}$ ) and form a spatial network in the asphalt mixture, increasing the mechanical properties, and aggregate sliding at the interface allocates stress, and reduces stress concentration, thereby improving the integral strength of asphalt matrix.

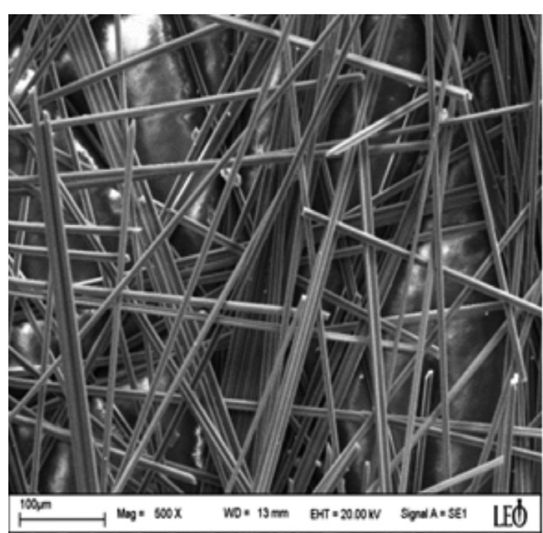

a) carbon fibre

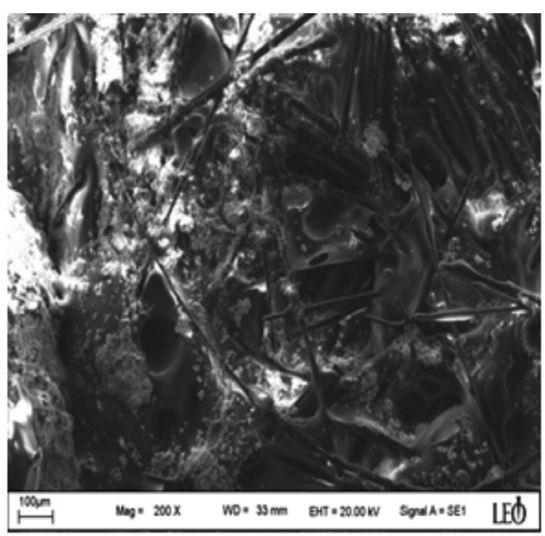

b) asphalt mixture containing carbon fibre

Figure 1. Images from Scanning Electron Microscope

\subsection{Preparation of specimens}

The amounts of CF contents were selected between $0.3 \%$ and $0.8 \%$ by weight of bitumen in the previous investigations (Cleven, 2000; Wiljanen, 2003). In this research, the CF contents were selected 

in the mixtures were chosen as $12.5 \mathrm{~mm}$. The dry process was used to minimise the main problems of clumping or balling of fibres in the asphalt mixtures. The aggregate and bitumen were heated in an oven at a temperature of at $165^{\circ} \mathrm{C}$. The $\mathrm{CF}$ was first mixed with the hot aggregate, and then the bitumen was added to this CF-aggregate mixture and mixed for $45 \mathrm{~s}$ using a mechanical blender. The prepared mixture samples were compressed with a Marshall device, and asphalt concrete specimens prepared in triplicate for each additive percentage were obtained.

Marshall control and CF-modified specimens used in this study were coded $\mathrm{B}, \mathrm{B} / 0.3 \mathrm{CF}, \mathrm{B} / 0.5 \mathrm{CF}$, and $\mathrm{B} / 0.7 \mathrm{CF}$, respectively.

\section{Testing program}

\subsection{Marshall stability, flow, and Marshall Quotient tests}

Marshall mix design procedure is typically used to optimise asphalt mixtures and to verify satisfactory voids in mixtures. The test is conducted on the specimens that contain different asphalt content to determine the optimum binder content (obc) produced 4\% air voids. The Marshall Quotient (MQ, $\mathrm{kN} / \mathrm{mm}$ ) is calculated as the ratio of stability $(\mathrm{kN})$ to flow $(\mathrm{mm})$, representing ratio approximation of load to deformation under the certain experimental conditions. Marshall Quotient is used as a measure of the pavement resistance to permanent deformation in the service life (Zoorob \& Suparma, 2000).

In this study, compacted specimens used in the Marshall Stability, ITSM, Creep Stiffness, ITS, and moisture resistance tests were prepared in consonance to ASTM D1559 Standard Test Method for Resistance to Plastic Flow of Bituminous Mixtures Using Marshall Apparatus. The specimens were compacted by Marshall compactor using 75 blows per each side of the specimen (101.6 $\mathrm{mm}$ in diameter and $63.5 \mathrm{~mm}$ thick).

\subsection{Indirect Tensile Stiffness Modulus test}

Stiffness modulus is an important parameter used to analyse the behaviour of the pavement under the traffic load and determine the performance of the pavement. Indirect Tensile Stiffness Modulus test that is identified by BS EN 12697-26:2018 Bituminous Mixtures. Test Methods. Stiffness standard is a non-destructive test and has been characterised as a potential means of measuring the stiffness properties of pavement (Figure 2). 
In the test performed with the Universal Testing Machine, the stiffness modulus $\left(S_{m}\right)$ value of the mixture in MPa was calculated by the following equation:

$$
S_{m}=\frac{L(v+0.27)}{D t},
$$

where $L$ is the peak value of the applied vertical loads; $D$ is the average amplitude of the horizontal deformation obtained from the load pulses, $\mathrm{mm}$; $t$ is the average thickness of the specimen, $\mathrm{mm} ; v$ is the Poisson ratio (0.35). The experiment is typically carried out at $20^{\circ} \mathrm{C}$, but in this study, specimens were also tested at $0{ }^{\circ} \mathrm{C}$ and $40^{\circ} \mathrm{C}$.

\subsection{Creep Stiffness test}

The Creep Stiffness test identified by BS EN 12697-25:2016 Bituminous Mixtures. Test Methods. Cyclic Compression Test standard is used to evaluate the resistance of the pavement to permanent deformations caused by traffic loads. Conditions under which an unconfined static uniaxial Creep Stiffness test (Figure 2) is carried out are:

a) $40^{\circ} \mathrm{C}$ standard test temperature, $60^{\circ} \mathrm{C}$ in hot climates;

b) 2 minutes pre-loading at $0.01 \mathrm{MPa}$ under conditioning stress;

c) constant load stress equal to $0.1 \mathrm{MPa}$ during the test;

d) test time: 1-hour loading and 1-hour unloading. During the test, axial deformation is measured as a function of time. Since the initial height of the specimen is known, the axial strain $(\varepsilon)$ and stiffness modulus $\left(S_{\text {mix }}\right)$ at any loading time determined by the Eq. (2):

$$
S_{\text {mix }}=\frac{\text { Applied } \operatorname{stress}(\sigma)}{\text { Axial } \operatorname{strain}(\varepsilon)} .
$$

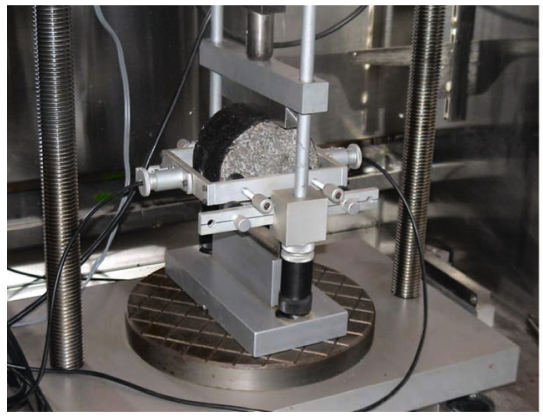

a) Indirect Tensile Stiffness Modulus

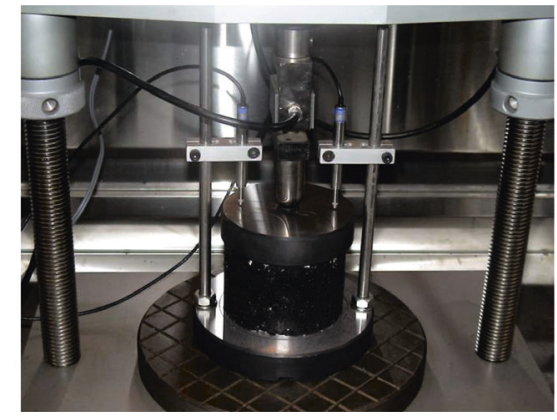

b) Creep Stiffness

Figure 2. Universal Testing Machine equipment 
The Indirect Tensile Strength (ITS) test is performed at a loading rate of $51 \mathrm{~mm} / \mathrm{min}$ by using the Marshall apparatus as stated in ASTM D6931-17:2017 Standard Test Method for Indirect Tensile (IDT) Strength of Asphalt Mixtures. The test involves loading of the cylindrical specimen with compressive loads acting in parallel and along the vertical diametrical plane. The Indirect Tensile Strength test is conducted to determine the cohesion ability of asphalt mixtures and to evaluate the tensile properties that cause cracking in the pavement. The Indirect Tensile Strength value is calculated as stated in the following Eq. (3):

$$
I T S=\frac{2 P_{\max }}{\pi t d}
$$

where ITS is the Indirect Tensile Strength, $\mathrm{kPa} ; P_{\max }$ is the applied load, $\mathrm{kN}$; $t$ is the thickness of specimen, $\mathrm{mm}$; and $d$ is the diameter of specimen, $\mathrm{mm}$.

\subsection{Resistance to moisture damage}

When water is present in the asphalt mixtures, this damages the bond between the asphalt and the aggregate and lead to stripping. The magnitude of this damage varies depending on the moisture sensitivity of the mixture. Therefore, the AASHTO T283 Standard Method of Test for Resistance of Compacted Asphalt Mixtures to Moisture-Induced Damage test is used to evaluate the adhesion, cohesion, and peeling ability of asphalt mixture underwater influence and thus the moisture sensitivity of mixture.

The test is applied to compressed samples with an air void level of 7\%. Firstly, three samples are selected as dry and tested with ITS test without moisture conditioning. Also, three more are selected to be conditioned by saturating with water (average 70\% saturation level) followed by a freeze cycle $\left(-18{ }^{\circ} \mathrm{C}\right.$ for $\left.16 \mathrm{~h}\right)$ and subsequently having a warm-water soaking cycle $\left(60^{\circ} \mathrm{C}\right.$ water bath for $\left.24 \mathrm{~h}\right)$. These specimens are then subjected to the ITS test.

The Indirect Tensile Strength values of the conditioned samples are divided by the ITS values of the dry samples, and so the Indirect Tensile Strength Ratio (ITSR) of the samples is determined. Mixtures having an ITSR below 0.7 are less resistant to moisture damage, and mixtures having an ITSR above 0.7 are relatively more resistant. 


\section{Results and discussion}

\subsection{Marshall stability and flow}

The aggregate-CF blends were mixed and compacted with bitumen in proportions of $4.0 \%, 4.5 \%, 5.0 \%, 5.5 \%$, and $6.0 \%$, respectively, to determine the optimum bitumen content (obc) of each of the $\mathrm{B}, \mathrm{B} / 0.3 \mathrm{CF}$, $\mathrm{B} / 0.5 \mathrm{CF}$, and $\mathrm{B} / 0.7 \mathrm{CF}$ mixtures. The optimum bitumen content values of the mixtures were determined as $4.9 \%, 5.0 \%, 5.1 \%$, and $5.3 \%$, respectively. Marshall design results obtained from the compacted specimens at the obc are given in Table 5. These results are the average values of the three specimens.

Table 5 shows that the addition of $\mathrm{CF}$ to the asphalt mixtures led to an increase at the Marshall stability values and to decrease at the flow values, compared to control mixtures. This increase in Marshall stability shows that the mixture under traffic loads has increased resistance to rutting and plastic deformation (shoving). On the other hand, reductions in flow values reflect the ability of asphalt mixtures to withstand gradual settlements and movements in the sub-grade without cracking. Since the flow value also points to rutting parameter, it is concluded that these mixtures resist for more extended periods without deformation under traffic loads. Moreover, Table 5 shows that the stability values of the $0.3 \%$ and $0.5 \% \mathrm{CF}$ added mixtures are increased, but the stability values of the $0.7 \% \mathrm{CF}$ added mixtures are slightly increased. This result is interpreted as follows: a large amount of $\mathrm{CF}$ in the mixture causes lower contact points among aggregates, so the stability decreases. Similarly, an increase in CF content decreases the flow value, and when the $\mathrm{CF}$ content is more than $0.5 \%$, the flow values are tending to increase.

Table 5. Marshall design results

\begin{tabular}{|c|c|c|c|c|}
\hline \multirow{2}{*}{ Property } & \multicolumn{4}{|c|}{ Mixture type } \\
\hline & B & $\mathrm{B} / 0.3 \mathrm{CF}$ & $\mathrm{B} / 0.5 \mathrm{CF}$ & $\mathrm{B} / 0.7 \mathrm{CF}$ \\
\hline Optimum binder content, $\%$ & 4.90 & 5.00 & 5.10 & 5.30 \\
\hline Aggregate bulk specific gravity, $\mathrm{g} / \mathrm{cm}^{3}$ & 2.634 & 2.634 & 2.634 & 2.634 \\
\hline Mix bulk specific gravity, $\mathrm{g} / \mathrm{cm}^{3}$ & 2.391 & 2.403 & 2.409 & 2.413 \\
\hline Air void, \% & 2.97 & 2.47 & 2.23 & 2.08 \\
\hline Voids in mineral aggregate, $\%$ & 10.36 & 10.41 & 10.44 & 10.45 \\
\hline Marshall stability, kN & 18.29 & 19.71 & 20.60 & 19.32 \\
\hline Flow, mm & 3.12 & 2.95 & 2.81 & 2.90 \\
\hline Marshall Quotient, kN/mm & 5.86 & 6.68 & 7.33 & 6.66 \\
\hline
\end{tabular}


In this study, MQ values were also calculated to evaluate the deformation resistance of all mixtures. The Marshall Quotient value, a measure of the resistance of materials to shear stresses and permanent deformations, is regarded as an indication of the resistance of asphalt mixtures to permanent deformation. The asphalt mixture specimens containing CF have high values of MQ than that of the control mixtures (Table 5). It is seen that the best result among the tested specimens was obtained from $\mathrm{B} / 0.5 \mathrm{CF}$ mixture specimens. This result shows that the addition of CF increases the resistance to permanent deformation of the mixtures by $25 \%$.

\subsection{Indirect Tensile Stiffness Modulus and Creep Stiffness}

The Indirect Tensile Stiffness Modulus (ITSM) results of control and CF-added mixtures at $0{ }^{\circ} \mathrm{C}, 20{ }^{\circ} \mathrm{C}$, and $40{ }^{\circ} \mathrm{C}$ are given in Table 6 and Figure 3.

The test results showed that the stiffness modulus of the asphalt mixtures increased with increasing CF content in the mixture. Especially the most essential improvements in the ITSM values of CF-added mixtures were obtained at $40{ }^{\circ} \mathrm{C}$. The stiffness modulus of asphalt mixtures modified with $0.3 \%, 0.5 \%$, and $0.7 \%$ CF increased by $1.38,1.51$, and 1.44 times, respectively, compared to the control asphalt mixtures. The highest increase in the stiffness modulus of the modified mixtures was obtained from the B/0.5CF asphalt mixtures. This highest increase has shown that the increase in stiffness modulus is due to the high tensile modulus and the low elongation ability of CFs. Fibres in the CF specimens have a random dispersion in different directions that firmly bond aggregate particles inside the mixture and prevent them from moving, hence making the

Table 6. Indirect Tensile Stiffness Modulus and Creep Stiffness test results

\begin{tabular}{cccrr}
\hline \multirow{2}{*}{ Property } & \multicolumn{5}{c}{ Mixture type } \\
\cline { 2 - 5 } & \multicolumn{5}{c}{ B/O.3CF } & \multicolumn{1}{c}{ B/O.5CF } & B/O.7CF \\
\hline \multicolumn{5}{c}{ Indirect Tensile Stiffness Modulus at, MPa } \\
\hline $0^{\circ} \mathrm{C}$ & 10640.50 & 11788.00 & 15571.00 & 12100.50 \\
$20^{\circ} \mathrm{C}$ & 1953.50 & 2058.50 & 2313.00 & 2170.00 \\
$40^{\circ} \mathrm{C}$ & 335.50 & 461.60 & 507.31 & 484.54 \\
\hline \multicolumn{5}{c}{ Creep Stiffness at 1-hour loading at, MPa } \\
\hline $60^{\circ} \mathrm{C}$ & 37.42 & 58.79 & 67.76 & 70.50 \\
\hline
\end{tabular}

Fibre on Performance Properties of Asphalt Mixtures 


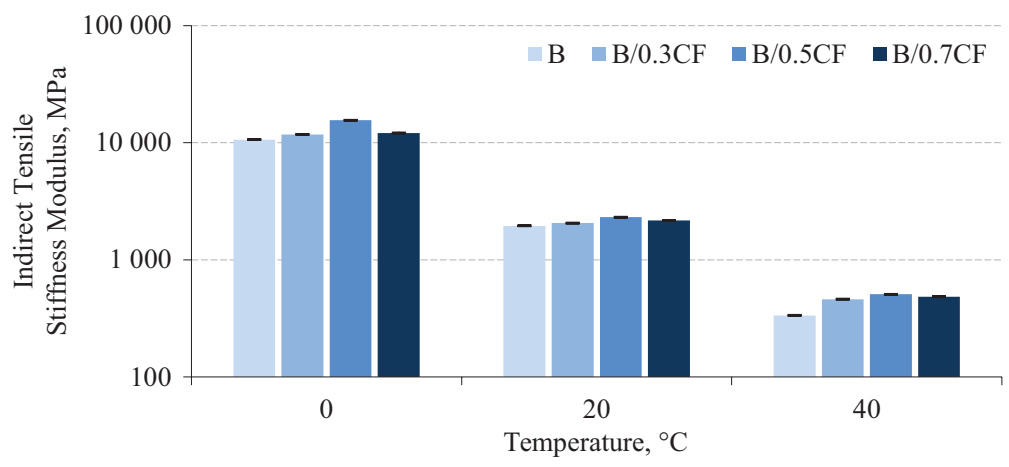

Figure 3. Indirect Tensile Stiffness Modulus values of the control and carbon fibre asphalt mixtures

mixture stiffer. However, a significant increase in the amount of CF in the mixture causes a large surface area to be coated with the bitumen; as a result, the aggregate particles and $\mathrm{CF}$ are not be covered entirely with bitumen so that a looser mixture and a low hardness modulus are obtained.

The Creep Stiffness test results of the mixtures are given in Table 6 and Figure 4. The Creep Stiffness values of the asphalt mixtures have continuously increased due to the increase in $\mathrm{CF}$ content in the mixtures. The Creep Stiffness of asphalt mixtures modified with $0.3 \%, 0.5 \%$, and $0.7 \% \mathrm{CF}$ have increased by $1.57,1.81$ and 1.88 times at $40{ }^{\circ} \mathrm{C}$ and by $1.54,1.79$ and 2.25 times at $60^{\circ} \mathrm{C}$, respectively, compared with the control asphalt mixtures. These results show that the addition of CF to the mixtures significantly increases the resistance of the pavements to permanent deformation at high temperatures in pavements under traffic loads.

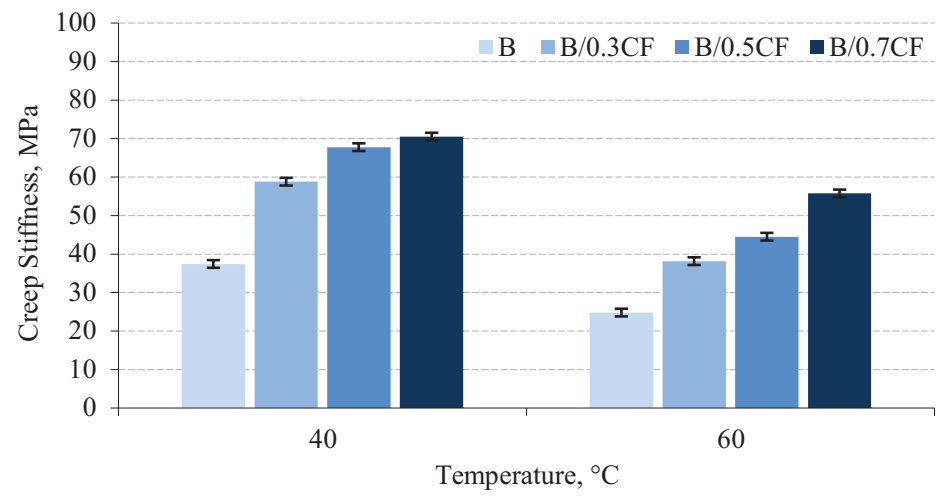

Figure 4. Creep Stiffness values of the control and carbon fibre asphalt mixtures 


\subsection{Indirect Tensile Strength}

The effect of CF content on the Indirect Tensile Strength (ITS) of the asphalt mixtures is given in Table 7 and Figure 5.

The addition of $0.3 \%, 0.5 \%$, and $0.7 \% \mathrm{CF}$ to asphalt mixtures have increased the both $I T S_{d r y}$ by 1.1,1.2, and 1.2 times and ITS cond by 1.1, 1.2, and 1.2 times, respectively, compared to control mixtures. Consequently, it is be concluded that the addition of $\mathrm{CF}$ as a reinforcement considerably improved the bonding properties between the bitumen and aggregate. In other words, mixtures prepared with CF provide stronger cohesive strength compared to control mixtures. Additionally, the relationship between ITSR and different types of mixtures is given in Figure 5. The Indirect Tensile Strength Ratio values of the asphalt mixtures have continuously increased due to the increase in CF content in the mixtures. The B/0.7CF mixture has a maximum ITSR value (0.956). This maximum value indicates that $\mathrm{CF}$ has a positive effect on moisture sensitivities of the asphalt mixtures.

Table 7. Indirect Tensile Strength test results

\begin{tabular}{|c|c|c|c|c|}
\hline \multirow{2}{*}{ Property } & \multicolumn{4}{|c|}{ Mixture type } \\
\hline & B & $\mathrm{B} / 0.3 \mathrm{CF}$ & $\mathrm{B} / 0.5 \mathrm{CF}$ & $\mathrm{B} / 0.7 \mathrm{CF}$ \\
\hline Indirect Tensile Strength of dry subset, ITS $S_{d r y}, \mathrm{kPa}$ & 763.00 & 845.00 & 917.11 & 923.50 \\
\hline Indirect Tensile Strength of condition subset, ITS cond, $_{1} \mathrm{kPa}$ & 717.22 & 801.06 & 872.17 & 882.87 \\
\hline Indirect Tensile Strength Ratio, ITS cond $/ I T S_{d r y}$ & 0.940 & 0.948 & 0.951 & 0.956 \\
\hline
\end{tabular}

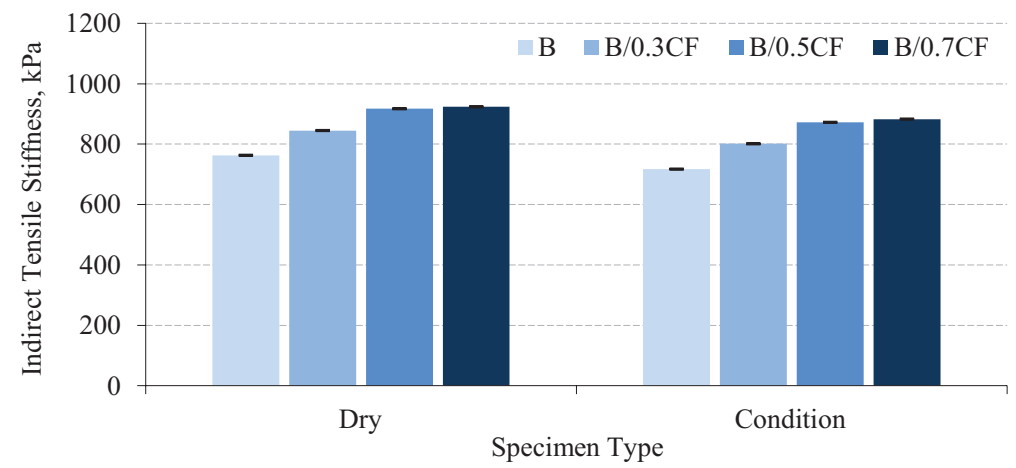

Figure 5. Indirect Tensile Stiffness values of the control and carbon fibre asphalt mixtures 


\section{Conclusions}

In this study, the impact of carbon fibre additive on the performance properties of asphalt mixtures was investigated. The following results were obtained.

1. The results of Marshall Stability and flow tests have indicated an increase in stability of asphalt mixtures with the carbon fibre additive, and a decrease in flow values of mixtures take place. Hence, carbon fibre added mixtures had high Marshall Quotient values. These high values indicate that carbon fibre additive has increased the resistance of mixtures against shear stresses and permanent deformations. The best results were obtained from B/0.5CF asphalt mixtures, with a $25 \%$ increase.

2. The Indirect Tensile Stiffness Modulus and Creep Stiffness test results have shown that the addition of carbon fibre significantly alters the behaviour of asphalt mixtures. As stated for the Indirect Tensile Stiffness Modulus results, the addition of $0.5 \%$ of carbon fibre has extended the permanent deformation resistance of mixtures by $51 \%$ at $40{ }^{\circ} \mathrm{C}$. Also, the addition of $0.7 \%$ of carbon fibre has increased permanent deformation resistance of mixtures by 2.25 times at $60{ }^{\circ} \mathrm{C}$.

3. The Indirect Tensile Stiffness results have shown that the addition of carbon fibre additive significantly increased the durability and the cohesion ability of asphalt mixtures. To add more, the Indirect Tensile Stiffness ratios of the specimens have indicated that mixtures had a high moisture resistance to water damage. This high moisture resistance signifies that carbon fibre has contributed to improving the adhesion between aggregate and asphalt in the mixture as a reinforcement additive.

Experimental results show that the addition of carbon fibre provides a positive contribution to the performance properties of asphalt pavements. This result has practical implications for the design of the pavements that are of high performance and safety.

\section{REFERENCES}

AASHTO T283 Standard Method of Test for Resistance of Compacted Asphalt Mixtures to Moisture-Induced Damage

Abtahi, S. M., Sheikhzadeh, M., \& Hejazi, S. M. (2010). Fiber-reinforced asphalt-concrete- a review. Construction and Building Materials, 24(6), 871-877. https://doi.org/10.1016/j.conbuildmat.2009.11.009 
ASTM C-127 Standard Test Method for Relative Density (Specific Gravity) and Absorption of Coarse Aggregate

ASTM C-128 Standard Test Method for Relative Density (Specific Gravity) and Absorption of Fine Aggregate

ASTM C-88 Standard Test Method for Soundness of Aggregates by Use of Sodium Sulfate or Magnesium Sulfate

ASTM D6931-17:2017 Standard Test Method for Indirect Tensile (IDT) Strength of Asphalt Mixtures

ASTM D113 Standard Test Method for Ductility of Asphalt Materials

ASTM C131 Standard Test Method for Resistance to Degradation of Small-Size Coarse Aggregate by Abrasion and Impact in the Los Angeles Machine

ASTM D1559 Standard Test Method for Resistance to Plastic Flow of Bituminous Mixtures Using Marshall Apparatus

ASTM D2170/D2170M Standard Test Method for Kinematic Viscosity of Asphalts

ASTM D36/D36M Standard Test Method for Softening Point of Bitumen (Ring-and-Ball Apparatus)

ASTM D5 Standard Test Method for Penetration of Bituminous Materials

ASTM D70 Standard Test Method for Density of Semi-Solid Asphalt Binder (Pycnometer Method)

ASTM D-854 Standard Test Methods for Specific Gravity of Soil Solids by Water Pycnometer

BS EN 12697-25:2016 Bituminous Mixtures. Test Methods. Cyclic Compression Test

BS EN 12697-26:2018 Bituminous Mixtures. Test methods. Stiffness

Chung, D. D., \& Chung, D. (2012). Carbon fiber composites. Elsevier.

Cleven, M. A. (2000). Investigation of the properties of carbon fiber modified asphalt mixtures (Master's thesis, Michigan Technological University).

Cong, P., Xu, P., \& Chen, S. (2014). Effects of carbon black on the anti-ageing, rheological and conductive properties of SBS/asphalt/carbon black composites. Construction and Building Materials, 52, 306-313. https://doi.org/10.1016/j.conbuildmat.2013.11.061

Echols, J. B. (1989). New mix method for fiber-reinforced asphalt. Public Works, 119(8).

Fitzgerald, R. (2000). Novel Application of Carbon Fiber for Hot Mix Asphalt Reinformortar and Carbon-carbon Pre-forms (Doctoral dissertation, Master's Thesis, Michigan Technological University, Houghton, MI, USA).

García, Á., Schlangen, E., van de Ven, M., \& Liu, Q. (2009). Electrical conductivity of asphalt mortar containing conductive fibers and fillers. Construction and building materials, 23(10), 3175-3181.

https://doi.org/10.1016/j.conbuildmat.2009.06.014

EN 12593:2015 Bitumen and Bituminous Binders - Determination of the Fraass Breaking Point

Jahromi, S. G., \& Khodaii, A. (2008). Carbon fiber reinforced asphalt concrete. Arabian Journal for Science \& Engineering (Springer Science \& Business Media BV), 33.
Fibre on Performance Properties of Asphalt Mixtures 
Krayushkina, K., Prentkovskis, O., Bieliatynskyi, A., Gigineishvili, J., Skrypchenko, A., Laurinavičius, A., Gopalakrishnan, K., \& Tretjakovas, J. (2016). Perspectives on usıng basalt fiber filaments in the construction and rehabilitation of highway pavements and airport runways. The Baltic Journal of Road and Bridge Engineering, 11(1), 77-83.

https://doi.org/10.3846/bjrbe.2016.09

Labib, M., \& Maher, A. (1999). Recycled plastic fibers for asphalt mixtures (No. FHWA NJ 2000-04).

Lee, S. J., Rust, J. P., Hamouda, H., Kim, Y. R., \& Borden, R. H. (2005). Fatigue cracking resistance of fiber-reinforced asphalt concrete. Textile Research Journal, 75(2), 123-128. https://doi.org/10.1177/004051750507500206

Lima, M. S. S., Thives, L. P., Haritonovs, V., \& Bajars, K. (2017, October). Red mud application in construction industry: Review of benefits and possibilities. In IOP Conference Series: Materials Science and Engineering (Vol. 251, No. 1, p. 012033). IOP Publishing. https://doi.org/10.1088/1757-899X/251/1/012033

Liu, X., \& Wu, S. (2011). Study on the graphite and carbon fiber modified asphalt concrete. Construction and Building Materials, 25(4), 1807-1811. https://doi.org/10.1016/j.conbuildmat.2010.11.082

Liu, X., Liu, W., Wu, S., \& Wang, C. (2014). Effect of carbon fillers on electrical and road properties of conductive asphalt materials. Construction and Building Materials, 68, 301-306. https://doi.org/10.1016/j.conbuildmat.2014.06.059

Liu, X., Wu, S., Li, N., \& Gao, B. (2008). Self-monitoring application of asphalt concrete containing graphite and carbon fibers. Journal of Wuhan University of Technology-Mater. Sci. Ed., 23(2), 268. https://doi.org/10.1007/s11595-006-2268-2

Morgan, P. (2005). Carbon fibers and their composites. CRC press.

Munn, W. D. (1989). Fiber-reinforced hot mix promises improved stability. Highways and Heavy Construction, 132(10).

Okuda, K. (1990). Carbon fibers and their composites. In Transactions of the Materials Research Society of Japan (pp. 119-139). Springer, Dordrecht. https://doi.org/10.1007/978-94-009-0789-8_8

Serfass, J. P., \& Samanos, J. (1996). Fiber-modified asphalt concrete characteristics, applications and behavior. Asphalt Paving Technology, 65, 193-230.

Vaitkus, A., Gražulytė, J., Vorobjovas, V., Šernas, O., \& Kleızıenė, R. (2018). Potential of mswi bottom ash to be used as aggregate in road buildıng materials. The Baltic Journal of Road and Bridge Eng., 13(1), 77-86. https://doi.org/10.3846/bjrbe.2018.401

Wang, Z., Gao, J., Ai, T., \& Zhao, P. (2014). Laboratory investigation on microwave deicing function of micro surfacing asphalt mixtures reinforced by carbon fiber. Journal of Testing and Evaluation, 42(2), 498-507. https://doi.org/10.1520/JTE20130118

Wiljanen, B. R. (2003). The pavement performance and life-cycle cost impacts of carbon fiber modified hot mix asphalt (Doctoral dissertation, Michigan Technological University). 
Wu, S., Ye, Q., Li, N., \& Yue, H. (2007). Effects of fibers on the dynamic properties of asphalt mixtures. Journal of Wuhan University of Technology-Mater. Sci. Ed., 22(4), 733-736. https://doi.org/10.1007/s11595-006-4733-3

Xiong, R., Fang, J., Xu, A., Guan, B., \& Liu, Z. (2015). Laboratory investigation on the brucite fiber reinforced asphalt binder and asphalt concrete. Construction and Building Materials, 83, 44-52. https://doi.org/10.1016/j.conbuildmat.2015.02.089

Zhao, S. Q. (2012). Study on Short Carbon Fiber Asphalt Concrete Marshall. In Advanced Materials Research (Vol. 529, pp. 446-449). Trans Tech Publications Ltd. https://doi.org/10.4028/www.scientific.net/AMR.529.446

Zoorob, S. E., \& Suparma, L. B. (2000). Laboratory design and investigation of the properties of continuously graded Asphaltic concrete containing recycled plastics aggregate replacement (Plastiphalt). Cement and Concrete Composites, 22(4), 233-242. https://doi.org/10.1016/S0958-9465(00)00026-3
Fibre on Performance Properties of Asphalt Mixtures 